Winter 12-2016

\title{
Persistent Organic Chemicals in the Pacific Basin Countries: An Overview
}

Bommanna G. Loganathan

Murray State University, bloganathan@murraystate.edu

Author(s) ORCID ID

0000-0001-5769-2579

Follow this and additional works at: https://digitalcommons.murraystate.edu/faculty

Part of the Environmental Chemistry Commons, Environmental Health and Protection Commons, Environmental Indicators and Impact Assessment Commons, Organic Chemistry Commons, and the Sustainability Commons

\section{Recommended Citation}

Loganathan, B.G. 2016. Persistent organic chemicals in the Pacific Basin countries: An overview. In. Persistent Organic Chemicals in the Environment: Status and trends in the Pacific Basin Countries I. Eds. Loganathan, BG., Khim, JS., Kodavanti, PR., Masunaga, S. ACS Symposium Series Vol. 1243. American Chemical Society and Oxford University Press. 1-15 pp. 


\title{
Chapter 1
}

\section{Persistent Organic Chemicals in the Pacific Basin Countries: An Overview}

\author{
Bommanna Loganathan* \\ Department of Chemistry and Watershed Studies Institute, \\ Murray State University, 1201 Jesse D. Jones Hall, \\ Murray, Kentucky 42071, United States \\ "E-mail: bloganathan@murraystate.edu
}

The Pacific Basin is a unique geographical region representing tropical, temperate and polar zones. This region is home to $2 / 3$ of world's population and consists of rapidly growing economies (countries) and highly developed countries. The Pacific Basin countries have had a history of use of persistent organic chemicals (POCs) at varying proportions during the last five decades. Due to diverse climatic and socio-economic conditions, the environment and biota in different countries in this basin have varying degrees of environmental contamination and effects on wildlife and humans. In this chapter, the historical background of POCs including, discovery, production, use, regulations/restrictions imposed, current status and possible future trends are reviewed especially focusing on the countries in the Pacific Rim. 


\section{Introduction}

The first half of $20^{\text {th }}$ century was the dawn of persistent organohalogen compounds. The chlorinated, brominated and fluorinated compounds were discovered and put to use during late 1800 s and 1900s respectively. These compounds are being used in consumer products such as cosmetics, medicines, foods, flavors, toiletries, paints, plastics and other industrial products. Many of these compounds protected animals and humans from deadly diseases, improved agricultural food production to meet the demands of increasing population, and improved the overall quality of our lives. Although these man-made chemicals benefitted man-kind, they have led to environmental contamination and have changed the quality of the environment, thus adversely affecting the health of animals and humans worldwide (1). Because these compounds are inert and stable under extreme environmental conditions, they are useful in many industrial, agricultural and public health applications. The chemical stability and recalcitrant properties of organohalogens, coupled with their widespread use, has led to global environmental contamination and harmful effects on wildlife and humans (2). To protect human health and the environment, the Stockholm Convention was adopted and put into practice by the United Nations Environment Program (UNEP) and listed (in 1995) the following persistent organic chemicals that are needed to be addressed globally: aldrin, chlordane, dieldrin, endrin, heptachlor, hexachlorobenzene, mirex, toxaphene, polychlorinated biphenyls (PCBs), dichlorodiphenyl trichloroethane (DDT), dioxins, polychlorinated dibenzofurans, polycyclic aromatic hydrocarbons, and brominated flame retardants. This list was subsequently (since 2001) expanded and new persistent organic compounds added to the Stockholm Convention List are: chlordecone, $\alpha-\mathrm{HCH}, \beta-\mathrm{HCH}, \gamma-\mathrm{HCH}$ (lindane), pentachlorobenzene (PeCB), tetrabromodiphenyl ether (tetra-BDE), perfluorooctanesulfonic acid (PFOS), endosulfans and hexabromocyclododecane (HBCD).

The Pacific Basin is a unique geographical region representing tropical, temperate and polar zones. This region is home to $2 / 3$ of world's population and consists of highly developed countries such as the United States, Canada, Japan, Australia and New Zealand etc., and rapidly growing countries, including China, Vietnam Indonesia, Philippines etc. These countries have had a history of use of organohalogens at varying proportions during the last several decades. Due to diverse climatic and socio-economic conditions, the environment and biota in different countries in this basin have had varying degrees of environmental contamination and effects on wildlife and humans. Since these compounds are ubiquitous, are resistant to degradation and cause long-term health effects, most of these compounds are severely restricted/banned from production and use in many countries, including countries in the Pacific Rim, since 1970s. The organohalogen compounds are commonly known as persistent organic pollutants (POPs), persistent organic chemicals (POCs) and persistent, bioaccumulative and toxic chemicals (PBTs). This chapter provides an overview of these synthetic organohalogens including, discovery, production, use, regulations/restrictions imposed, current status and possible future trends especially focusing on the countries in the Pacific Rim. 


\section{Early History and Timeline of POCs}

Figure 1 shows the summary of the timeline of persistent organic chemicals. The history of organochlorine pesticides began when Michael Faraday, who reported on June 16, 1825, the formation of "benzene hexachloride" by the reaction of benzene with chlorine in the presence of sunlight (3). Faraday did not recognize at that time that the product actually consisted of a mixture of isomers of hexachlorocyclohexane $(\mathrm{HCH})$. The discovery of insecticidal properties was missed during the early 1930s. In 1942, the name lindane was assigned to the active $\gamma$-isomer after Van Linden, discoverer of the $\delta$ and $\gamma$-isomers (4). The use of HCH isomers, known as technical HCH started in 1943, and the global consumption increased dramatically (estimated 6 million metric tons/year) since then. Also, during this period, in 1939, Paul Muller discovered the insecticidal activity of DDT (dichlorodiphenyl-trichloroethane). DDT was extremely effective against crop and household pests. DDT was used during/after World War II to control mosquitoes that spread malaria, typhoid fever, and cholera (5). Similar to lindane, DDT was first synthesized by Othmar Zeilder in 1873, long before its insecticidal property was found. During the first half of $20^{\text {th }}$ century several other chlorinated pesticides were introduced including, toxaphene, diene-organochlorine insecticides such as chlordane, mirex, Aldrin, dieldrin, endrin, and heptachlor.

In addition to the organochlorine insecticides, some other industrial chemicals either intentionally produced, or as resulting by-products of industrial processes are also of concern as POCs. These compounds include, polychlorinated biphenyls (PCBs), polynuclear aromatic hydrocarbons (PAHs), hexachlorobenzene (HCB), polychlorinated naphthalenes (PCNs), polychlorinated dibenzo- $p$-dioxins (PCDDs), polychlorinated dibenzofurans (PCDFs), polybrominated diphenylethers (PBDEs), perfluorinated compounds (PFCs) and chlorinated paraffins, etc.

The industrial chemical, polychlorinated biphenyl (PCB) was first synthesized as early as the 1880 s by Schmidt and Schultz (6) and large scale commercial production began in 1929. PCBs consist of 209 isomers and congeners from the mono-substituted 2-chlorobiphenyl to the fully substituted decachlorobiphenyl. Commercial PCB mixture range from 21\% (Aroclor 1221) to $68 \%$ chlorine (Aroclor 1268). PCB mixtures were produced for a variety of uses such as fluids in electrical transformers and capacitors, heat transfer fluids, lubricating and cutting oils, and as additives in plastics, paints, printing inks, adhesives and sealants (1). HCB was produced commercially as a fungicide for wheat in 1933 and also has had industrial uses in organic synthesis as a raw material for a variety of substances including synthetic rubber, a plasticizer for poly (vinyl chloride), an intermediate in dye manufacture etc. (7) In the following paragraphs, the production, use and regulations of select POCs in some Pacific Basin countries are highlighted. 


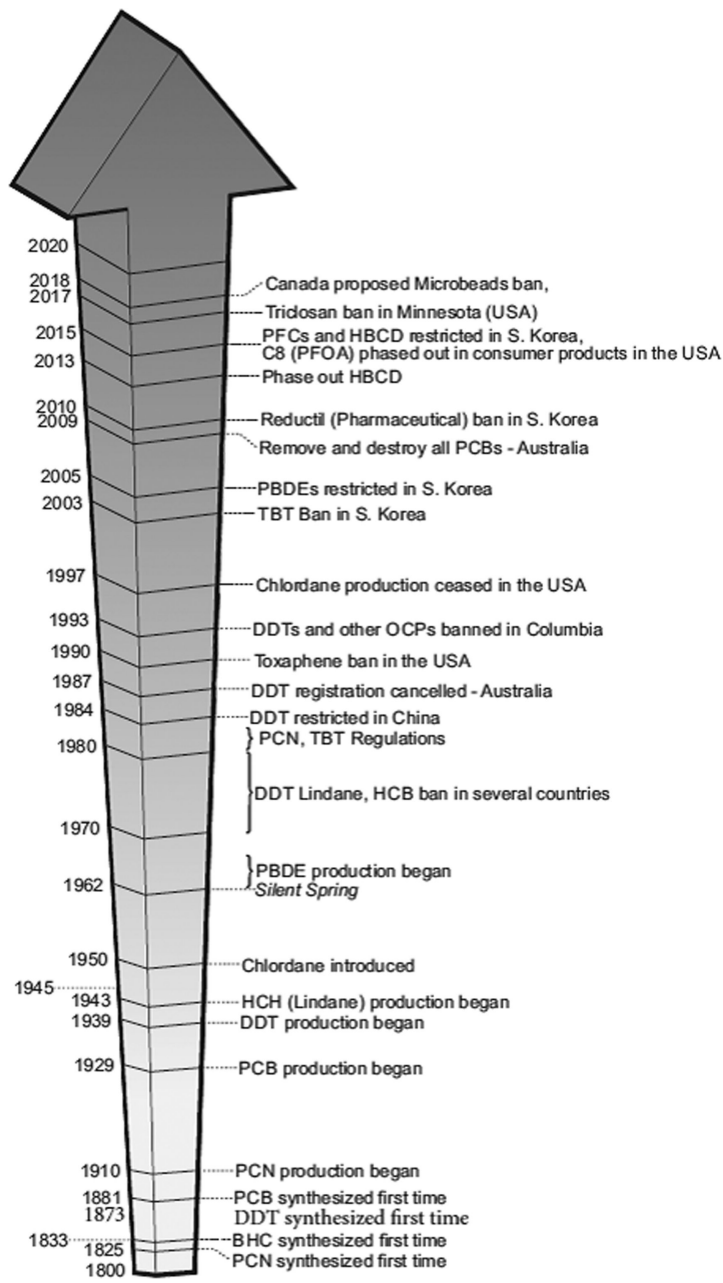

Figure 1. Timeline of persistent organic chemicals. The arrow indicates an increase in number of chemicals produced over the years. Despite regulations, the number of chemicals detected in environ-mental samples continues to increase in the present century, posing a threat to our environment and health.

\section{Restrictions/Ban on POCs in Some Countries in the Pacific Rim}

\section{United States and Canada}

The United States was one of the major producers of PCBs with an estimated $>600,000$ tons produced between 1930 and 1977 (8). Globally, over one million tons of PCBs were produced before the mid 1970s (8). The manufacture of PCBs stopped in the United States in August 1977. On April 19, 1999, the United States Environmental Protection Agency issued final regulations banning the 
manufacture of PCBs and the phasing out of most PCB uses. The largest use of PCBs prior to being discontinued in the late 1970s, was in closed systems such as electrical equipment, mainly capacitors and transformers $(9,10)$. In 1972, DDT was banned in the US for agricultural uses (11). In 1986, Toxaphene was banned in the US due its negative effect on human and animal health (12). Similarly, brominated flame retardants such as polybrominated diphenyl ethers, were also restricted/banned in several States in the US. In April 2007, the state of Washington passed a bill banning the use of PBDEs. The State of Maine Department of Environmental Protection found that all PBDEs should be banned. In August 2003, the State of California outlawed the sale of penta- and octaPBDE and products containing them, effective January 1, 2008. In May 2007, the legislature of the state of Maine passed a bill phasing out the use of DecaBDE. Some of the PBDEs such as penta- or octaBDE have been voluntarily withdrawn by manufacturers in the United States. Also, Minnesota become the first state in the US that proposed a ban on the sale of soaps and cleaning products that contain antibacterial compound triclosan as of January 1, 2017 (13). In addition, in January 2015, the final year of the PFOA (perfluorooctanoic acid) Stewardship Program, the US EPA proposed an additional Significant New Use Rule for C8/PFOA and 25 other long-chain PFCs (14).

In Canada, the manufacture, import, and sale of PCBs were made illegal in 1977 and release to the environment of PCBs were made illegal in 1985. However, Canadian legislation has allowed owners of PCB equipment to continue using PCB equipment until the end of its service life. The storage of PCBs has been regulated since 1988. Canada is signatory to several international agreements on the phase-out of a number of persistent toxic substances including PCBs (15). Canada banned DDT in 1972 because of its impact on humans and wildlife. Canada also banned the use of the most toxic PBDE compound (penta-PBDE) in 2005. In 2009, Canada added PFOS to a list of chemicals in legislation that must be eliminated from use. Toxaphene's effect on human and animal health led to a ban on its use in Canada in 1982 (16). Recently, the federal government of Canada has proposed a ban on microbeads in personal care products such as shower gels, facial scrubs and toothpastes, which will commence July 1, 2018. This Canadian Environmental Protection Act would prohibit the import, manufacture or sale of toiletries that contain microbeads that are $0.5 \mathrm{~mm}$ diameter or smaller (17).

\section{Colombia}

Colombia is located at the northwestern tip of South America and it is the fourth largest country on the continent. Colombia's ministry of environment is responsible for the definition of the environmental policies and regulations. In 2008, Colombia signed the Stockholm Convention on persistent organic pollutants. Colombia banned DDT and other organochlorines including, dieldrin, chlordane, mirex, pentachlorophenol, dicofol, BHC, heptachlor, lindane in 1993, and these are no longer in use. Colombia banned PCBs in 2008. According to the Ministry of Environment and Sustainable Development Resolution 222-2011, $30 \%$ of the total inventory of PCBs or wastes contaminated with PCBs must be eliminated by December 31, 2017. The $100 \%$ of the total inventory of 
PCBs or wastes contaminated with PCBs must be eliminated by December 31, 2028. Other compounds that are partially restricted are PBDEs (Law 1196-2008), perfluorinated compounds (Law 1196-2008), Heroin, methaqualone and meclocualona, and the substances that are listed in the Convention of Psychotropic 1971 (Resolution 826-2003 of Ministry of Social Protection.

\section{Australia}

Australia has a history of intensive use of organochlorine insecticides and industrial PCBs, but with gradual phasing out of these compounds through restrictions on agricultural use and the availability of less persistent and bioaccumulative alternatives (18). Australia is a signatory to the Stockholm Convention on Persistent Organic Pollutants. In 2003-2004, the federal agency estimated that 180 tons of deca-BDE product, 20 tons of penta-BDE product, and less than 10 tons of octa-BDE product were imported in raw form into Australia (18). This agency also reported a decrease in the use of about $90 \%$ of octa-BDE and approximately 70\% penta-BDE was seen in 2003-2004 compared to 1998-1999. From February 2007, octa-BDE was not allowed to be imported/manufactured and penta-, and deca-BDE are under review (18).

\section{Malaysia}

According to the PAN Asia and the Pacific, banned organochlorine pesticides such as DDTs are still in use in Malaysia (19). An article in a 21st Century Science and Technology headline reads, "With DDT Spryaing in Malaysia Can Show the World How to Control Dengue", the official announcement of the World Health Organization (WHO) in September 2006 gave a clean bill of health to the use of DDT for indoor spraying for controlling malaria reversed 30-year ban on DDT and offered promising way forward for also controlling the spread of mosquito-borne dengue fever $(20,21)$. According to the Director of WHO (Dr. Arata Kochi), “one of the best tools we have against malaria is indoor residual house spraying (IRS). Of the dozen insecticides WHO has approved as safe for house spraying, the most effective is DDT".

\section{Japan}

Japan manufactured PCBs under trade name Kanechlor. The total PCB production was estimated to be 60,000 tons until 1971. Japan banned PCBs in the year 1972 (22). Japanese Government enacted special law on PCBs to destroy all of the PCB containing wastes by the year 2023 (23). The cumulative amount of DDT and HCH production was 30,000 and 400,000 tons, respectively, until 1971. Japan imported chlordane compounds for termite control purposes. The use of chlordane in Japan was estimated to be 17,500 tons until it was banned in 1986 (24). HCB was banned in 1979; Aldrin, dieldrin, endrin were banned in 1981; heptachlor was banned in 1986; Toxaphene and mirex were banned 2002; $\alpha, \beta$, $\gamma$-HCHs were banned in 2010; endosulfan in 2014; pentachlorophenol, its salts and its esters were banned in 2016. PBDEs: tetra-, penta-, hepta-, and hexaBDEs 
banned in 2010. Deca-BDE is still in use. Perfluorinated compounds: PFOS, its salts were restricted in 2010. PCN was banned in 1979; pentachlorobenzene banned in 2010 and HBCD restricted in 2014 (25, 26).

\section{Republic of Korea (South Korea)}

DDTs and PCBs were banned in south Korea in 1971 and 1979 respectively. Import of PCBs were prohibited in 1984 (27). Lindane was banned in 1969, however, specific exemption as medicinal use until 2020 (28). Dieldrin was banned in 1971 and no longer used in S. Korea. Heptachlor and HCH were banned in 1979 and endosulfan was banned later in 2010 (29, 30). According to Eco-labeling policy some of the PBDEs were restricted beginning 2006 (31). Also some perfluorinated compounds were also restricted in 2015 with permanent exemption until development of alternatives (until 2025) (30). Reductil, a pharmaceutical chemical was banned in 2010 due to side effects such as stroke and myocardial infarction (32). Polyhexamethylene guanidine, oligo (2-(2-ethoxy) ethoxyethyl guanidine chloride)- humidifier germicides were banned in 2011 (33). Cleaning products containing nonylphenols were banned in 2002, this ban included $>0.1 \%$ nonylphenol products after 2006 (34). According to Shim et al. tributyltin (TBT) was banned in ships smaller than 4000 tonnage since 2000 and total ban imposed in 2003 (34). Hexabromocyclododecane (HBCD) was restricted in 2015, with permanent exemption chemical until development of alternative until 2020 (37).

\section{Emerging Compounds with Persistent Organic Pollutant-Like Properties Detected in the Pacific Basin Countries}

Table 1 shows the list of compounds detected in environmental and biological samples from the Pacific Basin countries (38-45).

In addition to compounds listed in the Table 1, a class of industrial chemicals used in plastics such as phthalates and phthalate metabolites were also of compounds of concern as endocrine disruptors. In August 2008, the United States Congress passed the Consumer Product Safety Improvement Act (CPSIA). The CPSIA bans the use of Di- $n$-butylphthalate (DBP), benzylbutyl phthalate (BBP), and Di(2-ethylhexyl)phthalate (DEHP) in amounts greater than $0.1 \%$ in all children's toys and some childcare products (46). In addition, the Congress also restricted, on an interim basis, diisononyl phthalate (DINP), di-n-octylphthalate (DNOP), and diisodecylphthalate (DIDP). The Consumer Product Safety Commission (CPSC) has also recommended banning diisobutylphthalate (DIBP), di-n-pentylphthalate (DnPP), di-n-hexylphthalate ((DHEXP) and dicyclohexylphthalate (DCHP) (46). Pharmaceuticals (with POP-like properties) including, antischizophernics, sedatives, antidepressants, antihypertensions, antihistamines, stimulants were also detected in wastewater treatment plant (47). 
Table 1. Emerging compounds with POP-like properties. Prepared based on references $(38-45)$.

Compound Name (CAS Number)

(i) Flame Retardants

1,2-Bis(2,4,6-tribromophenoxy)ethane (37853-59-1)

1,2-Bis(tetrabromophthalimido)ethane (32588-76-4)

5,6-Dibromo-1,10,11,12,13,13-hexachloro-11-tricyclo[8.2.1.02,9]tridecene

Decabromodiphenylethane (84852-53-9)

Di(ethylhexyl)tetrabromophthalate (26040-51-7)

Dechlorane Plus, Bis(hexachlorocyclopentadieno)cyclo-octane (13560-89-9)

2-Ethylhexyl-2,3,4,5-tetrabromobenzoate (183658-27-7)

Hexabromobenzene (87-82-1)

Hexabromocyclododecane, major isomers are $\alpha, \beta, \gamma$-HBCDD (3194-55-6)

Pentabromoethylbenzene (85-22-3)

Pentabromotoluene (87-83-2)

Tetrabromobisphenol A (79-94-7)

Tetrabromobisphenol A diallyl ether (25327-89-3)

Tetrabromobisphenol A bis(2,3-dibromopropyl) ether (21850-44-2)

1,2-Dibromo-4-(1,2-dibromoethyl)cyclohexane (3322-93-8)

2,4,6-tribromophenyl allyl ether (3278-89-5)

Tris(2-chloroethyl)phosphate (115-96-8)

Tris(1,3-dichloroisopropyl)phosphate (13674-87-8)

Short-chain chlorinated paraffins (85535-84-8 and 71011-12-6)

(ii) PFCs and other Industrial Chemicals

Perfluorooctane sulfonyl fluoride $(1,1,2,2,3,3,4,4,5,5,6,6,7,7,8,8,8-\quad$ POSF heptadecafluorooctane-1-sulfonyl fluoride) (307-35-7)

Perfluorooctane sulfonic acid $(1,1,2,2,3,3,4,4,5,5,6,6,7,7,8,8,8$ heptadecafluorooctane-1-sulfonic acid)(1763-23-1)

Perfluorooctane sulfonate Potassium salt (1,1,2,2,3,3,4,4,5,5,6,6,7,7,8,8,8-heptadecafluorooctane-1-sulfonate Potassium salt) (2795-39-3)

\section{Abbreviation}

BTBPE

BTBPIE

DBHC-TCTD

or $\mathrm{HCDBCO}$

(51936-55-1)

DBDPE

DEHTBP or TBPH

DP

EH-TBB or TBB

HBB

HBCD or

HBCDD

PBEB

PBT

TBBPA

TBBPA-DAE

TBBPA-DBPE

TBECH

TBP-AE or ATT

TCEP

TDCPP or TDCP

SCCP

PFOS

PFOS K

Continued on next page. 
Table 1. (Continued). Emerging compounds with POP-like properties. Prepared based on references (38-45).

\section{Compound Name (CAS Number)}

$\mathrm{N}$-ethyl-perfluorooctanesulfonamide

$(1,1,2,2,3,3,4,4,5,5,6,6,7,7,8,8,8$-heptadecafluorooctane-1-sulfonamide) (754-91-6)

Perfluorobutanoic acid (2,2,3,3,4,4,4-heptafluorobutanoic acid) (375-22-4)

Perfluroropentanoic acid (2,2,3,3,4,4,5,5,5-nonafluoropentanoic acid) (2706-90-3)

Perfluorohexanoic acid (2,2,3,3,4,4,5,5,6,6,6-undecafluorohexanoic acid) (307-24-4)

Perfluroroheptanoic acid $(2,2,3,3,4,4,5,5,6,6,7,7,7-$

tridecafluoroheptanoic acid) (375-85-9)

Perfluorooctanoic acid $(2,2,3,3,4,4,5,5,6,6,7,7,8,8,8$ -

pentadecafluorooctanoic acid) (335-67-1)

Perfluorononanoic acid $(2,2,3,3,4,4,5,5,6,6,7,7,8,8,9,9,9$ -

heptadecafluorononanoic acid) (375-95-1)

Perfluorodecanoic acid $(2,2,3,3,4,4,5,5,6,6,7,7,8,8,9,9,10,10,10$ nonadecafluorodecanoic acid) (335-76-2)

Perfluoroundecanoic acid $(2,2,3,3,4,4,5,5,6,6,7,7,8,8,9,9,10,10,11,11,11$-henicosafluoroundecanoic acid) (2058-94-8)

Perfluorododecanoic acid (2,2,3,3,4,4,5,5,6,6,7,7,8,8,9,9,10,10,11,11,12,12,12-tricosafluorododecanoic acid) (307-55-1)

8:2 fluorotelomer alcohol $(3,3,4,4,5,5,6,6,7,7,8,8,9,9,10,10,10$ heptadecafluoro-1-decanol) (678-39-7)

Components of Fire-Fighting Foams

Perfluorooctane sulfonate

Perfluorohexanesulphonate

Perfluorobutanesul-phonate

Perfluorooctanesulfonamide (PFOSA)Pperfluoro-decanoate

Perfluorononanoate

Perfluorooctanoate

Perfluoro-heptanoate

Perfluoroundecanoate

Perfluoro-hexanoate

Other Industrial Chemicals

\section{Abbreviation}

$N$-EtFOSA

PFBA

PFPeA

PFHxA

PFHpA

PFOA

PFNA

PFDA

PFUnDA

PFDoDA

$8: 2 \mathrm{FTOH}$

PFOS

PFHxS

PFBS

PFDA

PFNA

PFOA

PFHpA

PFUnDA

PFHxA

Continued on next page. 
Table 1. (Continued). Emerging compounds with POP-like properties. Prepared based on references (38-45).

Compound Name (CAS Number)

Bisphenol A, (4,4-dihydroxy-2,2-diphenyl propane) (80-05-7)

Bisphenol AF (hexafluorobisphenol A), (1,1,1,3,3,3-hexafluoro2,2-bis(4-hydroxyphenyl)propane) (1478-61-1)

Bis(2-ethylhexyl)tetrabromophthalate (26040-51-7)

(iii) Pharmaceuticals

Macrolide antibiotics

Carbamazepine

(iv) Personal Care Products

Musk Fragrances

1,3,4,6,7,8-hexahydro-4,6,6,7,8,8-hexamethylcyclopenta[g]-2benzopyrane (1222-05-5)

7-acetyl-1,1,3,4,4,6-hexamethyltetrahydeonaphthalene (1506-02-1)

\section{UV Stabilizers}

2-(3-t-butyl-2-hydroxy-5-methylphenyl)-5-chlorobenzotriazole (3896-11-5)

2,4-di-t-butyl-6-(5-chloro2H-benzotriazol-2-yl) phenol (3864-99-1)

2-(2H-benzotriazol-2yl)-4,6-di-t-pentylphenol (25973-55-1)
Abbreviation

BPA

BPAF

BEHTBP

HHCB

AHTN

UV-326

UV-327

UV-328

\section{Temporal Trends of Organohalogens and Emerging Pollutants in the Pacific Basin}

Trend monitoring studies are valuable in understanding the past history, present status and possible future trends of contamination by persistent organic pollutants (POPs) in the environment. During the last five decades, the production and use of many persistent organic chemicals/persistent organic pollutants have been severely restricted in several countries in the Pacific Rim. Figure 2 show a schematic representation of time trends of chlorinated, brominated, fluorinated compounds as well as emerging compounds of concern with persistent organic pollutant (POP)-like properties. Organochlorine compounds such as PCBs and chlorinated pesticides contaminate the environment and organisms very rapidly during the periods of their use in industries, agricultural or public health purposes. The contamination level declined after a ban or severe regulations on production and use of these chemicals were imposed, especially in the most developed countries. However, some developing countries in southeast Asia and Pacific region still use organochlorines to combat vector borne diseases such as malaria, dengue etc. Therefore, the end point of environmental pollution by 
chlorinated POPs may not be reached for several decades in the future. In contrast, fluorinated and brominated compounds are still being produced in large quantities (not phased out completely) and used in several consumer products in both developing and developed countries. Therefore, environmental contamination and exposure to wildlife and humans by these compounds continues. Similarly, emerging persistent compounds derived from pharmaceutical and personal care products (PPCP), with persistent organic pollutant-like properties, are detected in environmental and biological samples during the past decade are also of concern. Evidence of PPCP contamination and ecotoxicological effects on aquatic organisms and indirect effect on humans via antibiotic resistant bacteria are mounting. Considering the contamination trends profiles as depicted in Figure 2 , it can be predicted that the environmental contamination, human exposure, and health effects of brominated, fluorinated and other compounds with persistent organic pollutant-like properties will continue to be of concern for decades, not only to countries in the Pacific Basin, but also, on a global scale.

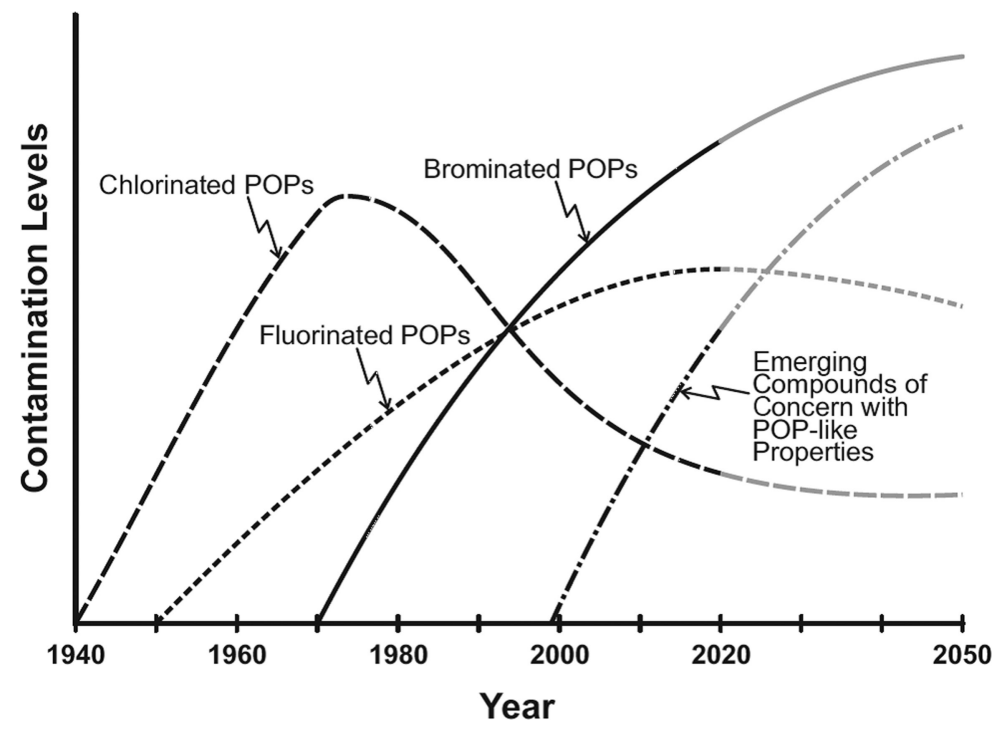

Figure 2. A schematic representation of time perspectives of classical POPs and compounds of concern with POP-like properties.

Human exposure to environmental pollutants has been attributed to the worldwide prevalence and dramatic increase of obesity and type 2 diabetes over the last four decades. The World Health Organization estimated 1.5 billion adults worldwide are overweight or obese and the number of type 2 diabetes increase from 153 to 347 million between 1980 and $2008(48,49)$. A recent study estimated the human cost of long-term low level chemical exposure to endocrine disrupting chemicals costs the United States $\$ 340$ billion in annual health care spending and lost wages (50).Typical examples are: PBDE flame retardant exposure leading to IQ points loss and intellectual disability in 43,000 cases with 11 million IQ points loss estimated cost $\$ 266$ billion dollars annually. Phthalates exposure 
and low testosterone resulting in increased early mortality (10,700 attributable dealths) estimated cost annually $\$ 8.8$ billion dollars and multiple exposure with autism and ADHD (attention deficit/hyperactivity disorder) in children $(\sim 5,900$ cases) estimated annual cost of $\$ 2.7$ billion (50). Considering the human cost of chemical exposure, it is important to take necessary steps to minimize exposure in a timely way to protect our environment and human health.

\section{Acknowledgments}

The author is thankful to the Murray State University Committee on Institutional Studies and Research (MSU-CISR) for awarding the 2016 Presidential Research Fellowship support in this endeavor.

\section{References}

1. Kodavanti, P. R. S.; Loganathan, B. G. In The International Encyclopedia of Public Health, 2nd ed.; Qua, R. R., Cockerham, W. C., Eds.; Elsevier, Inc.: Amsterdam, 2017; Volume 5, pp 359-366.

2. Loganathan, B. G.; Kannan, K. Global organochlorine contamination trends: An overview. AMBIO 1994, 23, 187-191.

3. Faraday, M. On new compounds of carbon and hydrogen, and on certain other products obtained during the decomposition of oil by heat. Philos. Trans. $R$. Soc. London 1825, 440-466.

4. Brooks, G. T. In Pesticide Chemistry of the $20^{\text {th }}$ Century; Plimmer, J. R., Ed.; ACS Symposium Series 37, American Chemical Society: Washington, DC, 1977; p 2.

5. Büchel, K. Chemistry of the Pesticides; Wiley-Interscience: New York, 1983.

6. Schmidt, H.; Schultz, G. Uber benzidin(a-di-amidophenyl). Ann. Chem. Liebigs. 1881, 207, 320.

7. Courtney, K. D. Hexachlorobenzene (HCB): A Review. Environ. Res. 1979, 20, 225-266.

8. Breivik, K.; Sweetman, A.; Pacyna, J. M.; Jones, K. C. Towards global historical emission inventory for selected PCB congeners - A mass balance approach 3. An update. Sci. Total Environ. 2007, 377, 296-307.

9. Faroon, O.; Olsen, J. Toxicological Profile for Polychlorinated biphenyls (PCBs); Agency for Toxic Substances and Disease Registry, U.S. Department of Health and Human Services: Atlanta, GA, 2000; 765.

10. Erickson, M. D. In. Analytical Chemistry of PCBs, 2nd ed.; CRC Press: Boca Raton, FL, 1997.

11. Kirk-Othmer. Insect Control Technology. In Encyclopedia of Chemical Technology, $3^{\text {rd }}$ ed.; Volume 13; Wiley-Interscience, New York, 1995.

12. Oehme, M.; Vetter, W. Toxaphene, a different environmental problem. Organohalogen Compd. 1999, 41, 561-564.

13. Hogue, C.; Erickson, B. Minnesota bans triclosan. C\&EN 2014, 92, 11.

14. Blum, A. Tackling toxics. Science 2016, 351, 1117. 
15. CEPA. The PCB Regulations under the Canadian Environmental Protection Act, 1999.

16. POPs Fact Sheet Series. Indigenous and Northern Affairs Canada. https://www.aadnc-aandc.gc.ca/eng/1316118124622/1316118213673 (accessed November 16, 2016).

17. Oosthoek, S. Canada proposes microbeads ban. $C \& E N$ 2016, $94,17$.

18. Mortimer, M.; Toms, L-M.; Mueller, J. F. In Global Contamination Trends of Persistent Organic Chemicals; Loganathan, B. G., Lam, P. K. S., Eds.; CRC Press Taylor and Francis Group: Boca Raton, FL, 2012; pp 129-162.

19. Rengam, S. V. Banned but Still in Use. Letters. PAN Asia and the Pacific, February 1, 2013.

20. Davis, M. P. With DDT Spraying in Malaysia Can Show the World How to Control Dengue; $21^{\text {st }}$ Century of Science and Technology, Summer 2006; pp 53-60.

21. WHO. WHO Gives Indoor Use of DDT a Clean Bill of Health for Controlling Malaria, September 15, 2006.

22. Loganathan, B. G.; Tanabe, S.; Hidaka, Y.; Kawano, M.; Hidaka, H.; Tatsukawa, R. Temporal trends of persistent organochlorine residues in human adipose tissue from Japan, 1928-1985. Environ. Pollut. 1993, 81, 31-39.

23. Ministry of Environment, Japan. http://www.env.go.jp/recycle/poly/ pcb_soukishori/ (accessed November 15, 2016).

24. Uesugi, S.; Kawamura, H.; Tsuji, M.; Tomita, S.; Maeda, S. In Encyclopedia of Pesticide Toxicity (in Japanese); Sanseidou Publishing Co.: Tokyo, pp 38-39.

25. Act on Evaluation of Chemical Substances and Regulation of Their Manufacture, etc., Japan. http://www.meti.go.jp/english/policy/ mono_info_service/kagaku/chemical_substances/ (accessed November 2016).

26. The National Implementation Plan of Japan under the Stockholm Convention on Persistent Organic Pollutants (modified in October 2016). http://chm.pops.int/implementation/NationalImplementationPlans/ NIPTransmission/tabid/253/default.aspx (accessed November 2016).

27. Hong, S.; Yim, U.; Shim, W.; Li, D.; Oh, J. Nationwide monitoring of polychlorinated biphenyls and organochlorine pesticides in sediments from coastal environment of Korea. Chemosphere 2006, 64, 1479-1488.

28. Yeo, H.-G.; Choi, M.; Sunwoo, Y. Seasonal variations in atmospheric concentrations of organochlorine pesticides in urban and rural areas of Korea. Atmos. Environ. 2004, 38, 4779-4788.

29. Kim, E. J.; Park, Y.-M.; Park, J.-E.; Kim, J.-G. Distributions of new Stockholm convention POPs in soils across South Korea. Sci. Total Environ. 2014, 476, 327-335.

30. Heo, J-W.; Kim, D. G.; Song, I-S.; Lee, G. Concentrations and gas particle partition of PCDD/Fs and DL-PCBs in the ambient air of Ansan area. $J$. Korean Soc. Atmos. Environ. 2010, 26, 517-532.

31. Kim, S.-K.; Khim, J. S.; Lee, K.-T.; Giesy, J. P.; Kannan, K.; Lee, D.-S.; Koh, C.-H. Emission, contamination and exposure, fate and transport, and 
national management strategy of persistent organic pollutants in South Korea. Dev. Environ. Sci. 2007, 7, 31-157.

32. Ha, Y. J.; Han, Y. J.; Choi, Y. W.; Myung, K. B.; Choi, H. Y. Sibutramine (reductil $\left.{ }^{\circledR}\right)$-induced cutaneous leukocytoclastic vasculitis: A case report. Ann. Dermatol. 2011, 23, 544-547.

33. Kim, J.-Y.; Kim, H. H.; Cho, K.-H. Acute cardiovascular toxicity of sterilizers, PHMG, and PGH: Severe inflammation in human cells and heart failure in zebrafish. Cardiovasc. Toxicol. 2013, 13, 148-160.

34. Shim, W. J.; Hong, S. H.; Kim, N. S.; Yim, U. H.; Li, D.; Oh, J. R. Assessment of butyl-and phenyltin pollution in the coastal environment of Korea using mussels and oysters. Marine Pollut. Bull. 2005, 51, 922-931.

35. Designation as Restrict Handling Material of Nonylphenols, 2006. Korea Ministry of Environment of Korea (KMOE). http:// www.me.go.kr/home/web/board/read.do?menuId=286\&boardMasterId $=1 \&$ boardCategoryId=39\&boardId=150193 (accessed November 16, 2016).

36. Restriction of Dioxin in Industries, 2007. Korea Ministry of Environment of Korea (KMOE). http://www.me.go.kr/home/web/board/read.do?menuId =286\&boardMasterId=1\&boardCategoryId=39\&boardId=158873 (accessed on November 16, 2016).

37. Base Set up of Management System for Hazardous Chemicals, 2015. Korea Ministry of Environment of Korea (KMOE). http:// www.me.go.kr/home/web/board/read.do?menuId=286\&boardMasterId $=1 \&$ boardCategoryId=39\&boardId $=472180$ (accessed on November 16, 2016).

38. Yin, J.; Meng, Z.; Zhu, Y.; Song, M.; Wang, H. Dummy molecularly imprinted polymerfor selective screening of trace biphenols in river water. Anal. Methods. 2011, 3, 173-180.

39. DiGangi, J.; Blum, A.; Bergman, A.; Lucas, D.; Schecter, A.; Scheringer, M.; Shaw, S. D.; Webster, T. F. San Antonio statement on brominated and chlorinated flame retardants. Environ. Health Perspect. 2010, 118, A516-A518.

40. Matsushima, A.; Liu, X.; Okada, H.; Shimohigashi, M.; Shimohigashi, Y. Bisphenol AF is a full agonist for the estrogen receptor ER $\alpha$ but a highly specific antagonist for ER $\beta$. Environ. Health Perspect. 2010, 118, 1267-1272.

41. Yamashita, N.; Yeung, L. W. Y.; Taniyasu, S.; Kwok, K. Y.; Petrick, G.; Gamo, T.; Guruge, K. S.; Lam, P. K. S.; Loganathan, B. G. In Global Contamination Trends of Persistent Organic Chemicals; Loganathan, B. G., Lam, P. K. S., Eds.; CRC Press: Boca Raton, FL, 2012; pp593-628.

42. Nakata, H.; Shinohara, R.; Murata S.; Sasaki, H. In Global Contamination Trends of Persistent Organic Chemicals; Loganathan, B. G., Lam, P. K. S., Eds.; CRC Press: Boca Raton, FL, 2012; pp 87-96.

43. Loganathan, B. G.; Phillips, M.; Mowery, H.; Jones-Lepp, T. L. Contamination profiles and mass loadings of macrolide antibiotics and illicit drugs from a small urban wastewater treatment plant. Chemosphere 2009, $75,70-77$. 
44. Taniyasu, S.; Yamashita, N.; Yamazaki, E.; Rostkowski, P.; Yeung, L. W. Y.; Kurunthachalam, S. K.; Kannan, K.; Loganathan, B. G. In Water Challenges and Solutions on a Global Scale; Ahuja, S., Andrade, J., Dionysiou, D., Hristovski, K., Loganathan, B. G., Eds.; ACS Sympsoum Series 1206; American Chemical Society: Washington, DC, 2015; pp 221-244.

45. Horii, Y.; Reiner, J. L.; Loganathan, B. G.; Kumar, K. S.; Sajwan, K.; Kannan, K. Occurrence and fate of polycyclic musks in wastewater treatment plants in Kentucky and Georgia, USA. Chemosphere 2007, 68, 2011-2020.

46. Sathyanarayana, S.; Karr, C. J.; Lozano, P.; Brown, E.; Calafat, A. M.; Liu, F.; Swan, S. H. Baby care products: Possible sources of infant phthalate exposure. Pediatirics 2008, 121, e260-e268.

47. Subedi, B.; Lee, S.; Moon, H.-B.; Kannan, K. Psychoactive pharmaceuticals in sludge and their emission from wastewater treatment facilities in Korea. Environ. Sci. Technol. 2013, 47, 13321-13329.

48. Kelishadi, R.; Poursafa, P.; Jamshidi, F. Role environmental chemicals in obesity: A systematic review on the current evidence. J. Environ. Pub. Health. 2013, 2013, 8, Aricle ID. 896789.

49. Ogden, C. L.; Carrol, M. D.; Curtin, L. R. Prevalence of overweight and obesity in the United States, 1999-2004. JAMA, J. Am. Med. Assoc. 2006, 295, 1549-1555.

50. Attina, T.; Hauser, R.; Sathyanarayana, S.; Hunt, P. A.; Bourguignon, J.-P.; Myers, J. P.; DiGangi, J. Exposure to endocrine-disrupting chemicals in the USA: A population-based disease burden and cost analysis. Lancet Diabetes Endorcrinol. 2016, 4, 996-10034. 